\title{
The Comparison of Different Nutrient Sources in Development of Aerobic Granular Sludge
}

\author{
C. Choerudin ${ }^{1,2}$, Ardiyan Harimawan ${ }^{1}$, and Tjandra Setiadi ${ }^{1,3, *}$ \\ ${ }^{1}$ Department of Chemical Engineering, Institut Teknologi Bandung (ITB), Jl. Ganesa 10, Bandung 40132, Indonesia \\ ${ }^{2}$ Department of Chemical Engineering, Institut Teknologi Nasional (ITENAS), Jl. P.H.H. Mustofa No.23, Bandung 40124, Indonesia \\ ${ }^{3}$ Center for Environmental Studies (PSLH), Institut Teknologi Bandung (ITB), Jl. Sangkuriang No. 42A Bandung 40135, Indonesia
}

\begin{abstract}
Aerobic granular sludge (AGS) as recent biological wastewater treatment has been developed in a modified sequencing batch reactor (SBR) using real textile wastewater. This experiment focused on comparing the effects of different nutrient sources, i.e. fine chemicals and fertilizer, on the characteristics of the AGS. The development of AGS conducted in a reactor that called as aerobic up-flow fluidized bed (AUFB) reactor. AUFB reactor allows the three-steps SBR operation namely filling-and-discharging, reaction, and settling. The developed AGS was characterized through some parameters i.e. physical characteristics (morphology, size distribution, settling velocity, specific gravity), granulation profile (MLSS and SVI), and removal performances (removal of COD and colour). The results showed that the developed AGS has a slight morphological difference as the effect of each nutrient source. Interestingly, metal ions contained in the nutrient sources affect the granulation profile and removal performances. Higher metal ions in the sources tent towards better profile (higher MLSS and lower SVI) but decreased removal performance (lower colour removal). In conclusions, this experiment suggests that the use of fertilizers as the nutrient source in developing AGS is comparable to the use of fine chemicals.
\end{abstract}

\section{Introduction}

Aerobic granular sludge (AGS) become a new standard technology in biological wastewater treatment in the near future [1]. By such a condition, the floccular activated sludge being developed into granular shape. Granular shape, which without carrier material, is very advantageous since it is denser and has very good settling properties. Significant amount of sustainable biomaterial named as alginate-like exopolysaccharides (ALE) can be isolated from the AGS waste $[2,3]$.

AGS technology applied commercially both on municipal and industrial wastewater treatment since first full-scale plant launched in 2005 under the name of Nereda ${ }^{\circledR}$ [1]. The amount of treatment plants (in operation, under construction or in design) on municipal wastewater is much more than on industrial wastewater as informed on its official website [4]. Furthermore, the application on industrial wastewater is limited on slaughterhouse and food processing industry in the Netherlands. However, application on more challenging industrial wastewater is still in research, i.e. textile wastewater.

Textile wastewater can be challenging for AGS technology since it containing synthetic dyes. Textile wastewater usually has high organic carbon and colour compound which is mostly azo dyes type [5]. However, anaerobic-aerobic systems are the most logical concept for dye degradation / colour removal [6]. This concept allows AGS technology being a proper system for the textile wastewater treatment.
Studies on aerobic sludge granulation on textile wastewater are scarce [5,7-11]. All of the study were conducted in laboratory scale and most of them were carried out on the artificial textile wastewater. Besides, most of previous study were conducted in conventional SBR operation which typically 5 steps per cycle namely filling, reaction, settling, discharging, and idling.

The objectives of this study are developing AGS from activated sludge using modified SBR and real textile wastewater. The modified SBR on this research means that the operation of SBR carried out on three steps per cycle: filling-and-discharging, reaction, and settling. The modified SBR designed as the strategy to conduct better granulation process.

As this research using a real textile wastewater, chemicals are used as additional nutrient. It is different to the previous studies that were using artificial wastewater - which are the chemical compositions are well defined. Therefore, this study also aimed to characterizing the AGS properties as the effects of different added nutrient sources.

\section{Materials and Methods}

This part covered explanation about the reactors, the wastewater characteristics, the nutrient composition, the seed sludge, the experimental setup, and the analytical methods.

Corresponding author: tjandra@che.itb.ac.id 


\subsection{Reactors}

The design of the reactor was adapted from previous study that is the aerobic up-flow fluidised bed reactor (AUFB) [12]. The reactor consisted of columns and an overhead clarifier. The AUFB was made of acrylic. The columns had diameter $5 \mathrm{~cm}$ with $120 \mathrm{~cm}$ and $200 \mathrm{~cm}$ height. The total working volume was $7.5 \mathrm{~L}$ and $9 \mathrm{~L}$. The reactor is illustrated in Fig. 1.

There was also a conventional SBR reactor used as the control. The reactor was a glass column with diameter of $9 \mathrm{~cm}$ and height of $100 \mathrm{~cm}$. Feed and air stream were located in the bottom of the reactor. The output stream was located on $70 \mathrm{~cm}$ from the bottom. Thus, the working volume of the reactor was $4.5 \mathrm{~L}$.

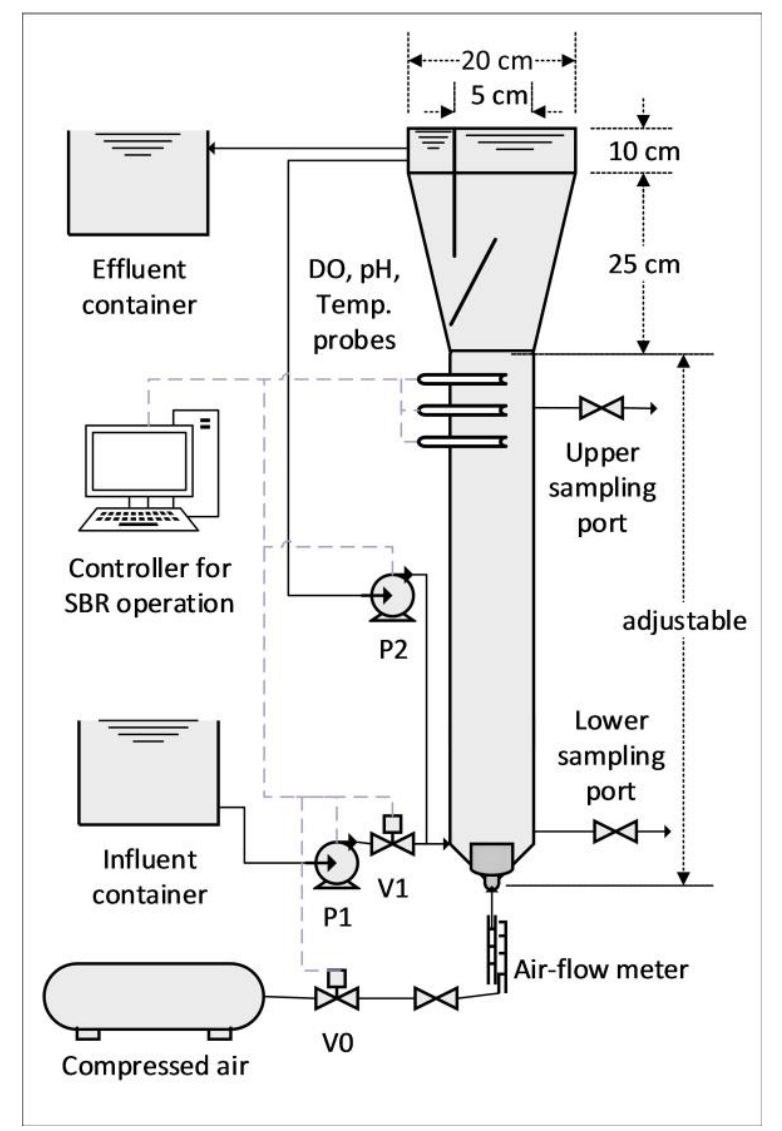

Fig. 1. Schematic representation of the aerobic up-flow fluidized bed (AUFB) reactor.

\subsection{Wastewater Characteristics}

The wastewater was from local textile industry which is located near Bandung City - Indonesia. The wastewater had COD, $\mathrm{BOD}_{5}$, and TSS value of $1550 \mathrm{mg} / \mathrm{L}, 441$ $\mathrm{mg} / \mathrm{L}$, and $92 \mathrm{mg} / \mathrm{L}$, respectively. The ammonium concentration was $<7 \mathrm{mg} / \mathrm{L}$ and the $\mathrm{pH}$ value was 9.9. Prior to the experiments, the $\mathrm{pH}$ value of wastewater set to around neutral by adding $\mathrm{HCl}$ and/or $\mathrm{NaOH}$. Then, the wastewater was added with different sources of nutrient that are fine chemicals or fertilizers.

\subsection{Added Nutrient Composition}

Nutrient from fine chemical sources was referred to previous study $[10,13]$. The nutrient consisted of $\mathrm{CH}_{3} \mathrm{COONa} 0.50 \mathrm{~g} / \mathrm{L}, \mathrm{NH}_{4} \mathrm{Cl} 0.16 \mathrm{~g} / \mathrm{L}, \mathrm{KH}_{2} \mathrm{PO}_{4} 0.23$ $\mathrm{g} / \mathrm{L}, \quad \mathrm{K}_{2} \mathrm{HPO}_{4} \quad 0.58 \quad \mathrm{~g} / \mathrm{L}, \quad \mathrm{CaCl}_{2} .2 \mathrm{H}_{2} \mathrm{O} \quad 0.07 \mathrm{~g} / \mathrm{L}$, $\mathrm{MgSO}_{4} .7 \mathrm{H}_{2} \mathrm{O} 0.09 \mathrm{~g} / \mathrm{L}, \mathrm{C}_{10} \mathrm{H}_{14} \mathrm{~N}_{2} \mathrm{Na}_{2} \mathrm{O}_{8} 0.02 \mathrm{~g} / \mathrm{L}$, and trace element solution $1 \mathrm{~mL} / \mathrm{L}$. The composition of the trace element solution was $\mathrm{H}_{3} \mathrm{BO}_{3} 0.15 \mathrm{~g} / \mathrm{L}, \mathrm{FeCl}_{3} .4 \mathrm{H}_{2} \mathrm{O}$ $1.50 \mathrm{~g} / \mathrm{L}, \mathrm{ZnSO}_{4} \cdot \mathrm{H}_{2} \mathrm{O} 0.12 \mathrm{~g} / \mathrm{L}, \mathrm{MnCl}_{2} .4 \mathrm{H}_{2} \mathrm{O} 0.12 \mathrm{~g} / \mathrm{L}$, $\mathrm{CuSO}_{4} .5 \mathrm{H}_{2} \mathrm{O} \quad 0.03 \mathrm{~g} / \mathrm{L}, \quad \mathrm{NaMoO}_{4} \cdot 2 \mathrm{H}_{2} \mathrm{O} \quad 0.06 \mathrm{~g} / \mathrm{L}$, $\mathrm{CoCl}_{2} \cdot 6 \mathrm{H}_{2} \mathrm{O} 0.15 \mathrm{~g} / \mathrm{L}$, and $\mathrm{KI} 0.03 \mathrm{~g} / \mathrm{L}$.

Nutrient from fertilizers was taken from NPK 25-7-7 and triple-superphosphate (TSP). The NPK contained $5 \% \mathrm{~N}, 7 \% \mathrm{P}_{2} \mathrm{O}_{5}, 7 \% \mathrm{~K}_{2} \mathrm{O}, 1.4 \% \mathrm{MgO}$, and $4 \% \mathrm{CaO}$. The TSP contained $46 \% \mathrm{CaH}_{2} \mathrm{PO}_{4}$.

\subsection{Inoculum}

Sludge for inoculation was the activated sludge from a local textile wastewater treatment plant. The sludge acclimatized in anaerobic and aerobic condition in 3 weeks. These two kinds of sludge were mixed up with ratio of 4:1. Anaerobic granular sludge, which was from local pulp and paper wastewater plant, was added 3.5\% of the mixture. Then, the inoculum was screened with sieve of $0.425 \mathrm{~mm}$ opening and TSS content was measured. Thus, the inoculum for starting up the process had size of $<0.425 \mathrm{~mm}$ and MLSS of $8092 \mathrm{mg} / \mathrm{L}$.

\subsection{Experimental Setups}

Total of three setups had been used based on the type of the reactors - i.e. conventional SBR 4.5 L (CSBR), AUFB 7.5 L (AUFB1) and AUFB 9 L (AUFB2). All reactors were operated in 6 hours cycle with three sequential phases: 15 min filling-and-discharging (anaerobic), $340 \mathrm{~min}$ reaction (40 min anaerobic +130 min aerobic, two times), and 5 min settling. Airflow rate was $0.3-0.8 \mathrm{~L} / \mathrm{min}$ and volume exchange ratio (VER) was $25 \%$ per cycle. At the start-up, inoculum comprised of $50 \%$ of CSBR volume, $50 \%$ of AUFB1 volume, and $25 \%$ of AUFB2 volume. The fine chemicals were mixed with the wastewater and added to CSBR and AUFB1. While, the fertilizers were mixed and added to AUFB2. Comparison of added nutrients is showed in

\section{Table 1.}

The change of sludge properties (i.e. MLSS and SVI) along granulation process was defined as the granulation profile. In AUFB1, the granules stability was tested by the change of feeding method that is the separation of wastewater stream from the $\mathrm{N}$ and $\mathrm{P}$ source stream. The test was as representation of inhomogeneity of system. In AUFB2, the granules stability was tested by increasing the ratio of $\mathrm{N}$ and $\mathrm{P}$ become 100:10:2. The developed granules were characterized through some physical parameters and also its performance on COD removal and decolourisation. 
Table 1. Comparison of added nutrient composition.

\begin{tabular}{ccccccc}
\hline Type & \multicolumn{2}{c}{$\begin{array}{c}\text { Artificial } \\
\text { Domestic } \\
\text { Sewage }\end{array}$} & \multicolumn{2}{c}{$\begin{array}{c}\text { Artificial } \\
\text { Textile } \\
\text { Wastewater }\end{array}$} & \multicolumn{2}{c}{$\begin{array}{c}\text { Real } \\
\text { Textile } \\
\text { Wastewater }\end{array}$} \\
\hline Ref. & {$[13]$} & {$[14]$} & {$[10]$} & {$[5,7,9]$} & AUFB1 & AUFB2 \\
\hline COD & 100 & 100 & 100 & 100 & 100 & 100 \\
\hline $\mathrm{N}$ & 5.1 & 10.8 & 3.4 & 3.8 & 5.0 & 5.0 \\
\hline $\mathrm{P}$ & 18.1 & 4.0 & 12.1 & 37.3 & 17.9 & 1.0 \\
\hline $\mathrm{S}$ & 1.4 & 2.6 & 0.9 & 0.3 & 1.4 & - \\
\hline $\mathrm{Ca}^{2+}$ & 2.2 & 0.4 & 1.5 & 0.8 & 2.2 & 0.8 \\
\hline $\mathrm{Mg}^{2+}$ & 1.0 & 1.8 & 0.7 & 0.2 & 1.0 & 0.2 \\
\hline $\mathrm{K}^{+}$ & 38.1 & 11.9 & 25.3 & 21.9 & 37.6 & 1.1 \\
\hline $\mathrm{Na}^{+}$ & 0.3 & 31.1 & 11.1 & 29.7 & 29.1 & - \\
\hline
\end{tabular}

\subsection{Analytical Methods}

The analytical parameters for the wastewater (i.e. influent and effluent) were COD, BOD, TSS, ammonium, $\mathrm{pH}$, and colour. The colour measurement using a scanning spectrophotometer in range of $400-$ $700 \mathrm{~nm}$. For the sludge, the parameters were MLSS, SVI, size distribution, specific gravity, and settling velocity. The morphology of sludge was observed under light microscope with associated camera digital and image processing software. The size distribution of sludge obtained by wet sieve analysis with opening 0.3 $\mathrm{mm}, 0.425 \mathrm{~mm}, 0.8 \mathrm{~mm}$, and $2.0 \mathrm{~mm}$. The specific gravity measurement was using pycnometer [15]. The settling velocity was defined as the settling time of single granules in $25 \mathrm{~cm}$ of volumetric cylinder. Other parameters that not described were referred to the APHA Standard Methods.

\section{Results and Discussion}

The results are split into three sub-section. First subsection is describing the granulation profile in the modified SBR. Second sub-section is describing the developed granules. Third sub-section is covering about the removal performance.

\subsection{Granulation profile}

The granulation profiles are depicted in Fig. 2. The diagram showed that MLSS in the start-up of CSBR and AUFB1 was $13.4 \mathrm{~g} / \mathrm{L}$ while in AUFB2 was $8.1 \mathrm{~g} / \mathrm{L}$. Most of the sludge had been washed out in the first cycle. All setup has sludge concentration around $2 \mathrm{~g} / \mathrm{L}$ after 3 days. The MLSS was $1.7 \mathrm{~g} / \mathrm{L}$ in AUFB $1\left(11^{\text {th }}\right.$ day) and $2.4 \mathrm{~g} / \mathrm{L}$ in AUFB2 (18 ${ }^{\text {th }}$ day). This result is comparable to previous study that is $4.7 \mathrm{~g} / \mathrm{L}$ in 27 days using conventional SBR on artificial textile wastewater with reducing settling time strategy [5]. But, in this experiment, the MLSS in the CSBR was drop to $0.43 \mathrm{~g} / \mathrm{L}$ on $11^{\text {th }}$ day. It suggests that the design of AUFB supports the modified SBR operation for granulation process than the conventional SBR.

Initial SVI was $73.4 \mathrm{~mL} / \mathrm{g}$ in AUFB1 and 121.1 $\mathrm{mL} / \mathrm{g}$ in AUFB2 based on Fig. 2. After the granulation started, the SVI value was $48.2 \mathrm{~mL} / \mathrm{g}$ in AUFB1 $\left(11^{\text {th }}\right.$ day) and $71.9 \mathrm{~mL} / \mathrm{g}$ in AUFB2 (18 $8^{\text {th }}$ day). The SVI were agreed with other result that is $67 \mathrm{ml} / \mathrm{g}$ in 27 days [5]. Small SVI value indicated that the granular sludge had been developed.

The stability test in each reactors was affecting the granulation profile, i.e. MLSS decreased and SVI increased. The change of feeding method was applied on the cycle after sampling on day $15^{\text {th }}$ in AUFB1 and on day $18^{\text {th }}$ in AUFB2. The SVI in AUFB1 increases sharply after the test. While, increasing the nutrient ratio in AUFB2 leads the sludge to form biofilm on the column wall. This effect also happened in other experiment using municipal wastewater [14]. The effect in AUFB1 was more dynamic than the effect in AUFB2.

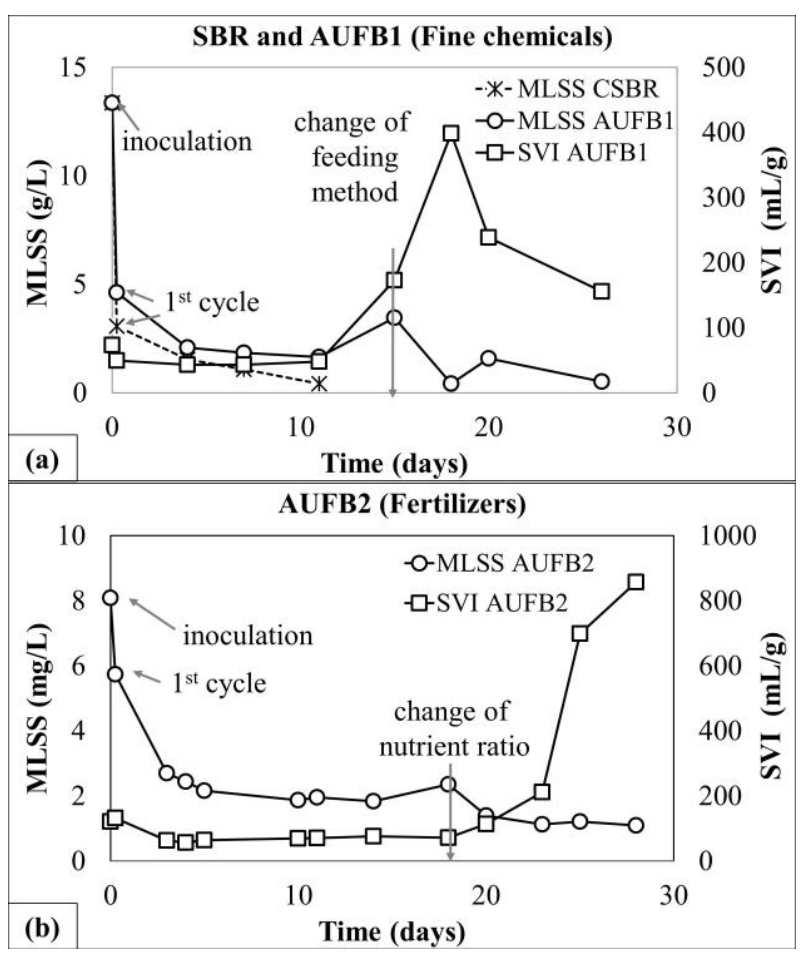

Fig. 2. Aerobic granulation profiles. $(\square=$ MLSS; $\circ=$ SVI)

\subsection{Physical Characteristics of Aerobic Granular Sludge}

This sub-section talks about physical characteristics of granules including morphology, size distribution, specific gravity, and settling velocity.

\subsubsection{Morphology}

The morphology of AGS under microscope shown in Fig. 3. It can be seen in Fig. 3a-3b that the inoculum consists of flocs and small granular sludge. After granulation periods, granules were formed and had slightly oval shape. But, granules in AUFB1 was more spherical than in AUFB2 by comparing the granules in 
Fig. 3c-3f. As refer to Fig. 3e, parts of anaerobic granular sludge is clumped in the new developed granules as can be seen as black dot in the granules' surface. This finding is agreed with previous study which also using anaerobic granular sludge as the seed [10]. Another thing to note that there were some cavities in the larger granules as seen in Fig. 3d and Fig. 3f.

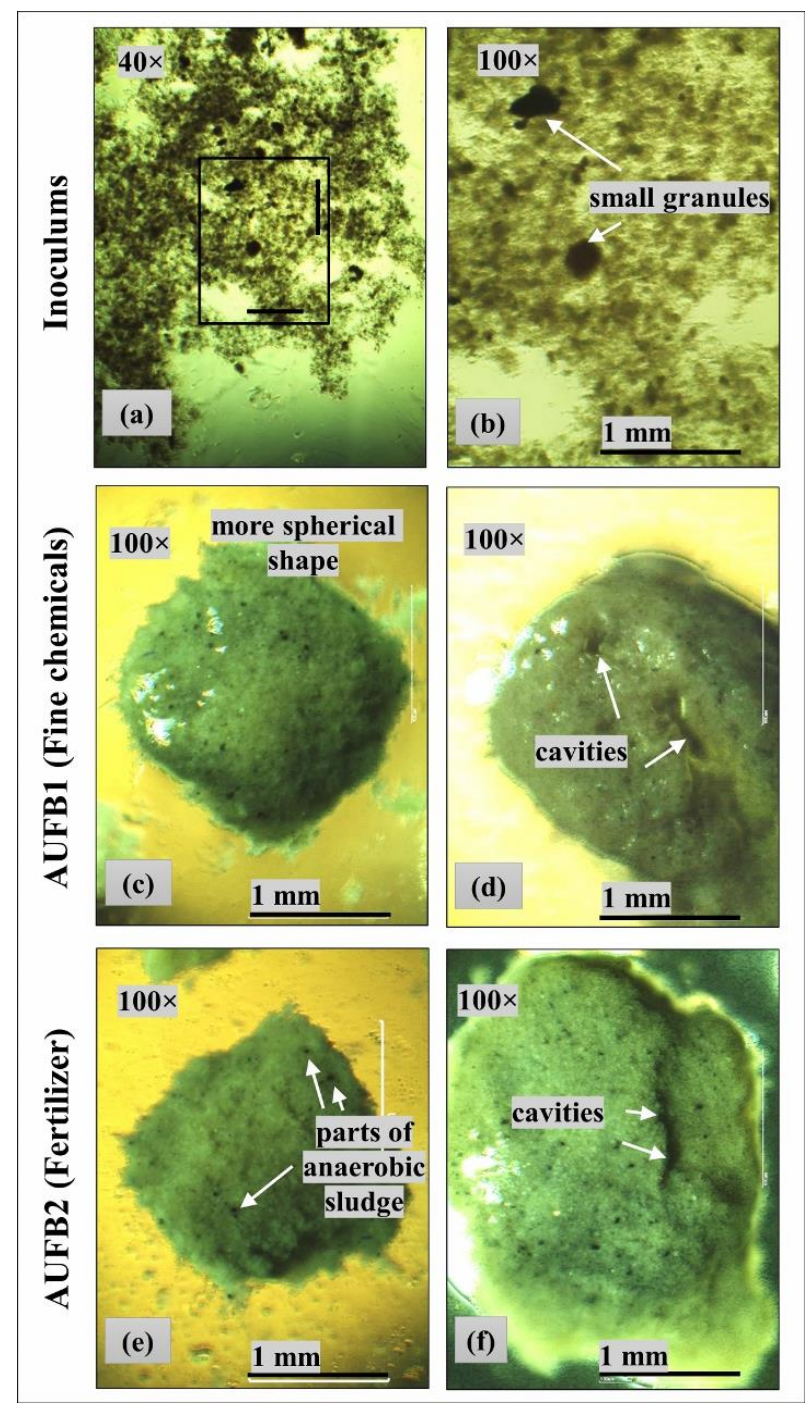

Fig. 3. Appearance of inoculum (a and b) and granular sludge from AUFB1 (b and c) and AUFB2 (e and f) under microscope.

\subsubsection{Size distribution}

Granular sludge was $4.12 \%$ of the total sludge in AUFB1 and $7.78 \%$ in AUFB2. It means that both sludge in AUFB1 and AUFB2 had smaller granules portion than flocs. This is agreed with another experiment on the artificial textile wastewater which had $30-45 \%$ of granules with size between $0.25-0.65 \mathrm{~mm}$ after 77 days [7]. However, full granulation cannot be reached due to short time process. In this experiment, flocs form had larger portion in total sludge because of the flocs had been accumulated in the overhead clarifier instead of washed out.
The distribution of sludge in the reactor is showed in Fig. 4. It shows that granules with size more than inoculum size was $80.6 \%$ in AUFB1 and $88.3 \%$ in AUFB2. This indicated that small granules in the inoculum were growing and become larger granules. In simply, granulation process was happened. The figure also depicted that granules with range size between $0.4-$ $2 \mathrm{~mm}$ were stable even after stability test.

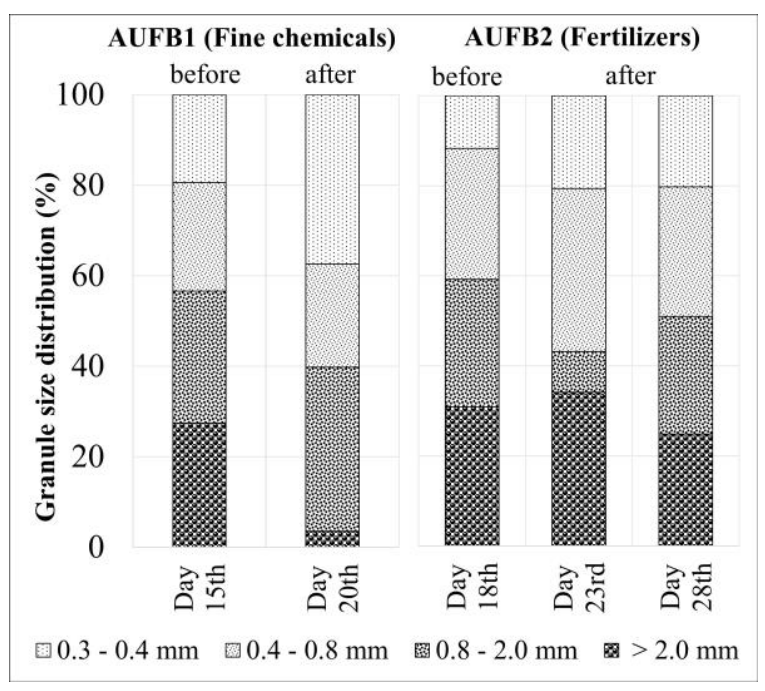

Fig. 4. Size distribution of granules before and after stability.

\subsubsection{Specific Gravity}

The specific gravity of granules in AUFB1 had range $1.021-1.069(1.039 \pm 0.016$ in average $)$ while the AUFB2 $1.038-1.039$. Specific gravity of granules in AUFB1 was slightly denser than in AUFB2. This is as the effect of different nutrient composition that is AUFB1 has higher phosphorus and metal ions ratio than AUFB2.

Granule with size range of $0.85-2 \mathrm{~mm}$ in AUFB1 had average specific gravity of $1.046 \pm 0.017$. But, granule with size $>2 \mathrm{~mm}$ was $1.033 \pm 0.013$. It means that larger size had lower specific gravity due to cavities which formed in larger granules as described previously.

\subsubsection{Settling velocity}

Settling characteristics of developed granule is shown in Fig. 5. Granular sludge from AUFB1 had settling velocity minimum of $13.3 \mathrm{~m} / \mathrm{h}$ and up to $44 \mathrm{~m} / \mathrm{h}$. In AUFB2, the minimum settling velocity was $11 \mathrm{~m} / \mathrm{h}$ and up to $36 \mathrm{~m} / \mathrm{h}$. Settling velocity of granule in AUFB1 was slightly better than AUFB2. It also can be seen that granule with larger size is faster to settle not only in AUFB1 but also in AUFB2. It can be concluded that higher ratio phosphorus and metal ions in the nutrient could increases the settling velocity of the granules. 


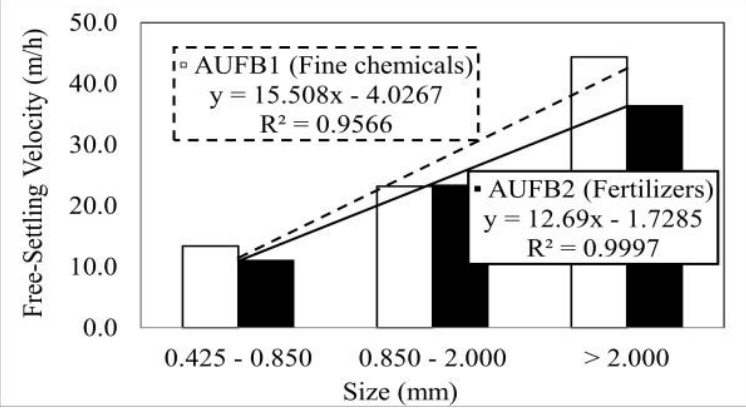

Fig. 5. Free-settling velocity of granules. (empty bar = AUFB1; filled bar = AUFB2; line = linear of AUFB1; dash = linear of AUFB2)

\subsection{Removal Performance}

The observed performance was the COD removal and the decolourisation. COD removal of AUFB1 and AUFB2 reached up to $84.5 \%$ in day $15^{\text {th }}$ and $85.1 \%$ in $18^{\text {th }}$, respectively. It means that there is no significant different between both systems. COD removal performance in this experiment is not that different to other experiments which are $80-85 \%$ [5,7,9]. It can be concluded that different sources of added nutrient did not affect the COD removal performance.

Change of feeding method in AUFB1 and nutrient ratio in AUFB2 decreases the COD removal performance. However, after several days, the performance reaches up again to around $80 \%$. This is can be seen in Fig. 6.

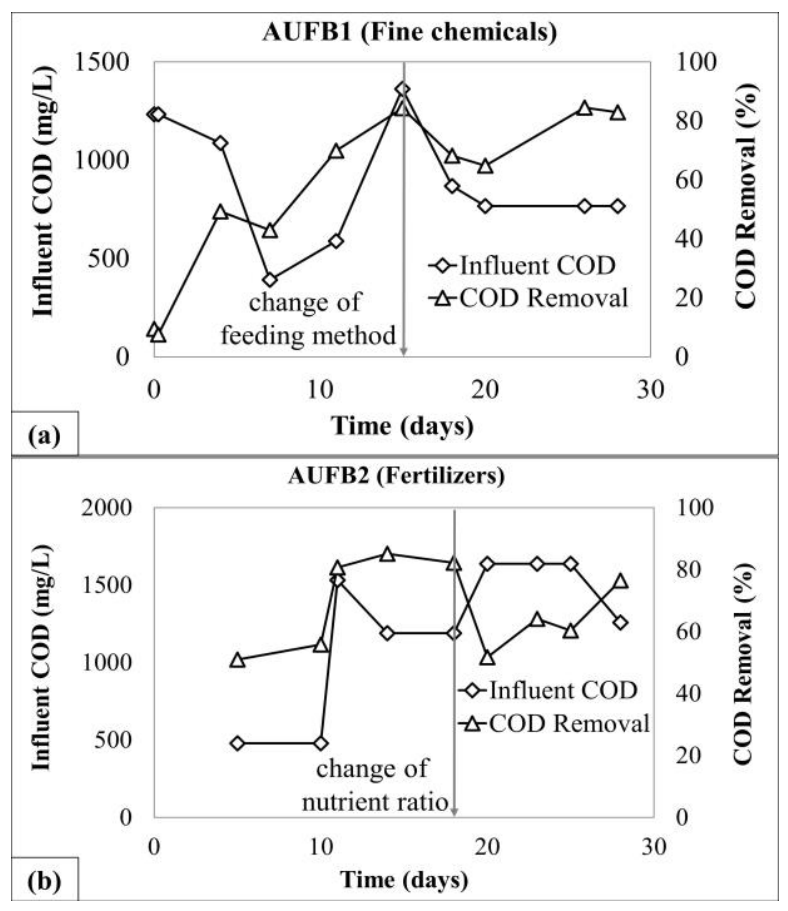

Fig. 6. COD removal performance along granulation.

In decolourisation performance, the AUFB1 has better performance than AUFB2 as the absorbance of effluent in AUFB 2 was below 0.2. In AUFB1, the absorbance of effluent was more than 0.2 while the added nutrients are mixed together in the influent reservoir. But, after the change of feeding methods, the absorbance was below 0.2. While in AUFB2, the effluent had absorbance $<0.2$. Interestingly, the absorbance was higher when the nutrient ratio being increased.

The result in Fig. 7 shows that the added nutrient affects the decolourisation performance as described previously. This is happened since metals ion (i.e. bivalent ions) could bind to the azo dyes and make the dye more recalcitrant [16]. This also can be regarded as the metal ions acted as the alternatives terminal acceptor which compete to the azo dyes (the targeted acceptor) [6]. In simply, the AUFB1 had lower decolourisation performance due to the higher metals ion contained in the added nutrients.
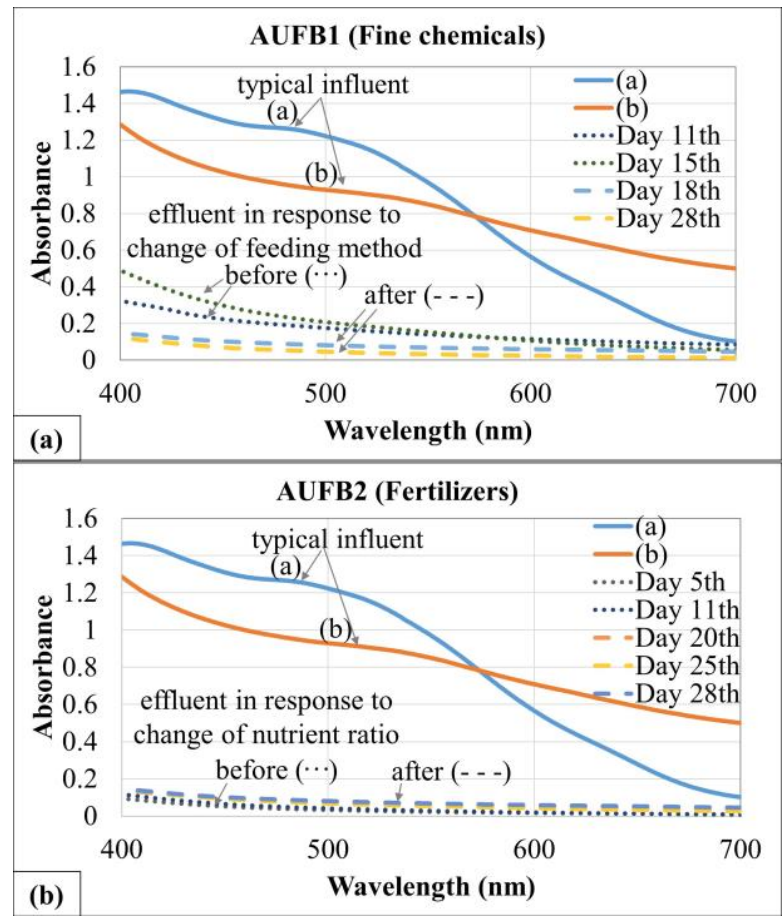

Fig. 7. Decolourisation performance along granulation.

\section{Conclusions}

This study is to investigate the process of aerobic granular sludge development using modified sequencing batch reactor and the effects of nutrient addition. It can be reported that the three-steps sequencing batch operation can be used for development of the aerobic granular sludge using real textile wastewater.

The main difference of using fine chemical or fertilizer as the added nutrition is the composition of metal ions. This difference affects some physical characteristics of the developed granules. Higher metal ion and phosphorus in the nutrient leads the production of smaller size, higher specific gravity, and better settling velocity. Metal ions in the added nutrition is good for the granulation but less desirable for the decolourisation. However, the use of fertilizer as the added nutrition source for granulation was comparable to the fine chemical source. 
The authors want to thank the Ministry of Research Technology and Higher Education of Indonesia (Kementerian Ristek-Dikti) for the scholarships and the program (Program Magister menuju Doktor untuk Sarjana Unggul, PMDSU). The authors would like also to thank the KWEF-AIT Research Grant (KARG) 2016 for a partial funding of this research.

\section{References}

1. A. Giesen, L. M. M. de Bruin, R. P. Niermans, and H. F. van der Roest, Water Pract. Technol. 8, wpt. 2013007 (2013).

2. Y. Lin, M. de Kreuk, M. C. M. van Loosdrecht, and A. Adin, Water Res. 44, 3355 (2010).

3. Y. M. Lin, K. G. J. Nierop, E. Girbal-Neuhauser, M. Adriaanse, and M. C. M. van Loosdrecht, Sustain. Mater. Technol. 4, 24 (2015).

4. (n.d.). Accessed on: August 2017. Available at: https://www.royalhaskoningdhv.com/en$\mathrm{gb} /$ nereda/nereda-wastewater-treatment-plants

5. A. M. T. Mata, H. M. Pinheiro, and N. D. Lourenço, Biochem. Eng. J. 104, 106 (2015).

6. F. P. van der Zee and S. Villaverde, Water Res. 39, 1425 (2005).

7. R. D. G. Franca, A. Vieira, A. M. T. Mata, G. S. Carvalho, H. M. Pinheiro, and N. D. Lourenço, Water Res. 85, 327 (2015).

8. T. C. Kee, H. H. Bay, C. K. Lim, K. Muda, and Z. Ibrahim, Desalination Water Treat. 54, 132 (2015).

9. N. D. Lourenço, R. D. G. Franca, M. A. Moreira, F. N. Gil, C. A. Viegas, and H. M. Pinheiro, Biochem. Eng. J. 104, 57 (2015).

10. K. Muda, A. Aris, M. R. Salim, Z. Ibrahim, A. Yahya, M. C. M. van Loosdrecht, A. Ahmad, and M. Z. Nawahwi, Water Res. 44, 4341 (2010).

11. K. Muda, A. Aris, M. R. Salim, Z. Ibrahim, M. C. M. van Loosdrecht, A. Ahmad, and M. Z. Nawahwi, Water Res. 45, 4711 (2011).

12. N. Kishida, A. Kono, Y. Yamashita, and S. Tsuneda, J. Water Environ. Technol. 8, 251 (2010).

13. J. J. Beun, A. Hendriks, M. C. M. van Loosdrecht, E. Morgenroth, P. A. Wilderer, and J. J. Heijnen, Water Res. 33, 2283 (1999).

14. J. J. Beun, M. C. M. van Loosdrecht, and J. J. Heijnen, Water Res. 36, 702 (2002).

15. M. C. M. van Loosdrecht, P. H. Nielsen, C. M. Lopez-Vazquez, and D. Brdjanovic, Experimental Methods in Wastewater Treatment, IWA Publishing, London (2016).

16. Y. Shimizu and T. Takagishi, J. Sericultural Sci. Jpn. 66, (1997). 